\title{
Prenatal multiple micronutrient supplementation impact on biochemical indicators during pregnancy and postpartum
}

\author{
Armando García-Guerra, MSc,(I) Lynnette M Neufeld, PhD, (') Sonia Hernández-Cordero, PhD, (1) \\ Juan Rivera, PhD, (1) Reynaldo Martorell, PhD, (2) Usha Ramakrishnan, PhD. ${ }^{(2)}$
}

\author{
García-Guerra A, Neufeld LM, Hernández-Cordero S, \\ Rivera J, Martorell R, Ramakrishnan U. \\ Prenatal multiple micronutrient supplementation \\ impact on biochemical indicators \\ during pregnancy and postpartum. \\ Salud Publica Mex 2009;5 I:327-335.
}

\begin{abstract}
Objective. The objective of this analysis was to test the impact of daily supplementation with multiple micronutrients (MM) during pregnancy on $\mathrm{Zn}$, vitamin $\mathrm{A}$ and folate status compared to iron only (Fe). Material and Methods. The study was carried out during 1997-2000 in a semi-urban community in Morelos state, Mexico.Women were randomly assigned to $M M(n=249)$ or Fe $(n=258)$ and received supplements daily $(6 \mathrm{~d} / \mathrm{wk})$ under supervision by the field team from recruitment (approximately 9 weeks pregnancy) until delivery. Blood samples were collected on a sub-sample of women at baseline, 32 weeks pregnancy and one month postpartum (IPP) and assessed for serum zinc, retinol and whole blood folate (baseline and IPP only). A breast milk sample was extracted at IPP and assessed for retinol content. Result. At baseline there was no significant difference between supplementation groups in mean $\mathrm{Zn}$, retinol or folate concentrations or the prevalence of deficiencies ( $\mathrm{Zn}$ $12.2 \%$, vitamin A $2.8 \%$, folate $5.3 \%$ ). Mean change in $\mathrm{Zn}$ and retinol concentrations from baseline to 32 weeks pregnancy did not differ between groups or between baseline and IPP for $\mathrm{Zn}$, retinol or folate. At IPP, there was a tendency $(\mathrm{p}=$ 0.09 ) towards a lower prevalence of folate deficiency/depletion in the MM group (10.0\%) than the Fe group (I8.5\%).
\end{abstract}

García-Guerra A, Neufeld LM, Hernández-Cordero S, Rivera J, Martorell R, Ramakrishnan U.

Efecto de la suplementación prenatal con micronutrimentos múltiples en indicadores bioquímicos durante el embarazo y el posparto. Salud Publica Mex 2009;5 1:327-335.

\section{Resumen}

Objetivo. Evaluar el efecto de la suplementación diaria con múltiples micronutrimentos (MM) durante el embarazo en el estado de zinc, vitamina A y folato comparado con la suplementación sólo con hierro ( $\mathrm{Fe}$ ). Material y métodos. El estudio se realizó en una comunidad semiurbana en el estado de Morelos, México, entre 1997 y 2000. Las mujeres fueron asignadas aleatoriamente a recibir un suplemento de MM $(n=249) \circ \mathrm{Fe}(\mathrm{n}=258)$ diariamente (6 días/semana), cuyo consumo fue supervisado por personal de campo, desde la evaluación basal (aproximadamente 9 semanas de gestación) hasta el parto. En una submuestra de mujeres participantes, se tomaron muestras de sangre venosa, a las 9 y 32 semanas de embarazo y al mes posparto (IPP). Se midieron las concentraciones séricas de zinc y retinol y la concentración de folato en sangre total, esta última sólo en la evaluación basal y al IPP. Además se colectó una muestra de leche materna al IPP, en donde se midió la concentración de retinol. Resultados. En la evaluación basal no hubo diferencias significativas entre grupos en las concentraciones promedio de zinc y retinol, ni en la concentración de folato o en la prevalencia de defi-

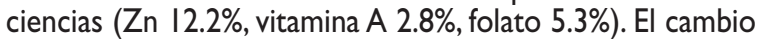
promedio en zinc y retinol de la evaluación basal a la semana 32 de embarazo, no fue diferente entre grupos, tampoco

Supported by the Thrasher Research Fund, NIH Grant HD-3453I-05, UNICEF, the Mexican Council for Science and Technology (Conacyt), and INSP, Mexico. None of the authors had any financial or personal conflict of interest.

(I) Centro de Investigación en Nutrición y Salud, Instituto Nacional de Salud Pública. Cuernavaca, Morelos, México.

(2) Hubert Department of Global Health, Rollins School of Public Health, Emory University, Atlanta, GA, USA.

Received on: August 29,2008 - Accepted on: April 22, 2009

Address reprint requests to: Mtro. Armando García Guerra. Dirección de Epidemiología de la Nutrición, Centro de Investigación en Nutrición y Salud (CINyS), Instituto Nacional de Salud Pública,Av. Universidad 655, col. Santa María Ahuacatitlan, 62 I00, Cuernavaca, Morelos, México. E-mail: garciaf@insp.mx 
Conclusions. MM supplementation during pregnancy did not improve zinc or vitamin A status compared to Fe only. There is some indication that folate status may have improved with MM supplementation despite low prevalence of deficiency. While lack of response in serum retinol may be explained by generally adequate status, the lack of impact on zinc status requires further exploration.

Key words: zinc; retinol; folic acid; randomized controlled trial; dietary supplements; Mexico entre la evaluación basal y al IPP en zinc, retinol o folato. Al IPP hubo una tendencia $(p=0.09)$ a menor prevalencia de deficiencia/depleción de folato en el grupo de MM (I0.0\%) que en el grupo Fe (I8.5\%). Conclusiones. La suplementación con MM durante el embarazo no mejoró el estado de zinc y vitamina A comparada con la suplementación sólo con $\mathrm{Fe}$. Sin embargo, el estado de folato puede haber mejorado con la suplementación con MM, a pesar de la baja prevalencia de deficiencia de folato. La falta de efecto en vitamina A podría ser explicada por el adecuado estado de la misma en las mujeres estudiadas y la falta de efecto en el estado de zinc requiere futura exploración.

Palabras clave: zinc; retinol; ácido fólico; ensayo controlado aleatorio; suplementos dietéticos; México
$\mathrm{D}$ uring pregnancy, metabolic demands are increased as a result of physiological and hormonal changes in the mother and growth of the fetus. ${ }^{1}$ During this period, micronutrients deficiencies may have serious consequences for pregnancy outcomes. Zinc deficiency in animal models causes intrauterine growth retardation (IUGR) and congenital malformations. ${ }^{2}$ In humans, zinc deficiency during pregnancy is associated with low birth weight, IUGR and preterm delivery., Vitamin A deficiency is associated with adverse maternal, fetal and neonatal outcomes and may be a cause of anemia. ${ }^{5}$ The relationship between maternal hemoglobin concentration and perinatal mortality is well documented ${ }^{6,7}$ and periconceptual folate status is important in the development of neural tube defects. ${ }^{8,9}$

Micronutrient deficiency during pregnancy continues to be an important public health problem throughout the world. In Mexican women 12 to 49 years of age, iron and zinc deficiency are high ( $40 \%$ and $30 \%$, respectively). ${ }^{10}$ In a large nationally representative nutrition survey, folate deficiency was detected in 5\% and vitamin A depletion in $4 \%$ of women of reproductive age. ${ }^{11}$

Although several multiple micronutrient supplementation trials have been conducted, the findings are mixed for birth outcomes. A recent Cochrane review of supplementation trials concluded that multiple micronutrient supplementation improves fetal growth compared to placebo but not compared to iron or iron-folate supplementation. ${ }^{12}$ In Nepal, multiple micronutrient supplementation during pregnancy was not associated with markers of inflammation ${ }^{13}$ and may be associated with higher early infant mortality. ${ }^{14}$ Evidence for the impact of multiple micronutrient supplementation on a number of outcomes is still considered inadequate and further research is required before a switch from iron- folate supplementation is implemented..$^{12}$ Few supplementation trials have reported biochemical markers of micronutrient status. Functional outcomes are often difficult to measure due to measurement imprecision or the need for large sample sizes and the documentation of impact on intermediary variables such as micronutrient status is vital. In Nepal, ${ }^{15}$ multiple micronutrient supplementation resulted in improved folate status during pregnancy and reduced the prevalence of riboflavin, vitamin $B_{6^{\prime}}$ vitamin $B_{12^{\prime}}$ folate, and vitamin $\mathrm{D}$ deficiencies.

We previously reported that a randomized controlled multiple micronutrient supplementation trial conducted in Mexico had no effect on birth weight, length or gestational age compared to iron only supplementation. ${ }^{16}$ In the same trial, hemoglobin concentration was lower in the multiple micronutrient group during the third trimester, with no lasting difference between the groups at one month postpartum. ${ }^{17}$ We report here the impact of daily supplementation with multiple micronutrients during pregnancy on zinc, vitamin A and folate status during pregnancy and 1 month postpartum, zinc and vitamin A in cord blood, and breast milk retinol concentration at one month postpartum in women who participated in a randomized controlled trial in Mexico, using supplementation with iron only as comparison.

\section{Material and Methods}

A detailed description of the study population, the intervention, data collection and primary results have been published previously. ${ }^{16-18}$ We will review the methods briefly here, with emphasis on those that are relevant to the assessment of micronutrients status. This study was approved by the Human Subjects Committee at Emory 
University, Atlanta, GA, USA, and the Research, Ethics and Biosecurity Commissions at National Institute of Public Health (INSP), Cuernavaca, Mexico. Women were invited to participate after receiving complete details of the study objectives procedures, risks and benefits and if interested, the consent declaration was read to the participants and if agreed, they were asked to sign or provide a finger print.

\section{Intervention}

All women participants were randomly assigned to receive a multiple micronutrient $(\mathrm{MM})$ or iron only $(\mathrm{Fe})$ tablet once daily from recruitment until delivery. Both tablets contained $60 \mathrm{mg}$ of iron in the form of ferrous sulfate and were identical in color and size. The MM tablet also contained 100 to $150 \%$ of the recommended dietary allowance ${ }^{19}$ for zinc, iron, vitamins $\mathrm{A}, \mathrm{C}, \mathrm{B}_{6^{\prime}}$ folate and several other micronutrients. The exact formula of the tablets has been published previously. ${ }^{16}$ Four color coded supplementation groups were created (two per type of supplement) to reduce the possibility of unblinding of the trial and tablets were distributed in color-coded bottles with the participants name and ID number written on the bottle. The supplement was distributed daily to each woman in her home by trained field workers who observed and noted consumption. The study field staff, investigators and the participating women remained blind to the treatment throughout the field stage and until after analyses of primary outcomes were completed. The analyses reported here were conducted after breaking the supplement code.

The study was carried out during 1997-2000 in semi-urban community in Morelos state, Mexico. A total of 873 women were assigned to treatment and 645 (73.9\%) completed the trial and resulted in a singleton live births. The reasons for loss to follow-up have been explained elsewhere. ${ }^{16,17}$ The original design was to obtain a venous blood sample from a $30 \%$ random subsample of all pregnancies, but samples were available for many more women and serum zinc was assessed on 565 (64.7\% of women recruited) $(\mathrm{MM}, \mathrm{n}=249 ; \mathrm{Fe}, \mathrm{n}=$ 258). Due to budgetary limitations, we assessed serum zinc for the follow-up visits (32 weeks pregnancy and one month postpartum) on a random sub-sample of those for whom baseline zinc had been assessed. For the same reason, serum retinol was assessed on a random sub-sample of women who had sample available at baseline and at least one of the two follow-up visits. The methodology for assessment of whole blood folate was implemented at INSP after data collection was underway. We therefore obtained samples on the last women recruited into the trial (approximately 100) and included only baseline and one month postpartum due to budgetary constraints. Cord blood and breast milk samples were collected from the first approximately 100 women enrolled in the study. Cord blood was assessed for zinc and retinol and breast milk for retinol.

\section{Data collection and sample analysis}

Women with confirmed or suspected pregnancy were identified through a monthly community census, provided with details of the study and offered an immunological urine test for pregnancy (Gestalatex, Applied Inc. Biotech, San Diego, USA). Duration of pregnancy was then estimated based on last menstrual period, except in the case of an uncertain date in which the woman was referred to receive an ultrasound examination. This method has been used successfully by our group in similar populations. ${ }^{20}$ Women with confirmed pregnancies of less than 13 completed weeks were provided with details of the study and invited to participate. Additional exclusion criteria for the present study included multiple pregnancies, use of micronutrient supplements and refusal to participate. ${ }^{16,17}$

Socio-economic, demographic and reproductive history information was collected by questionnaire at recruitment and height and weight were measured. Information on the status and progress of pregnancy was collected at three additional visits $(26,32$ and 37 weeks of pregnancy) and included weight, dietary intake and blood pressure. Details of the blood sampling and processing methods have been published previously. ${ }^{17}$ Briefly, a $7 \mathrm{ml}$ venous blood sample was taken at the field clinic by trained phlebotomists at baseline, 32 weeks pregnancy and one month postpartum. Trace element free collection tubes (Vacutainer, Becton Dicknson, Franklin Lakes, New Jersey, USA) and sample processing materials were used. Whole blood samples for folate determinations were collected on labeled filter paper (filter paper No. 903, S\&S, Inc., New York, NY, USA) and stored in sealed plastic bags with desiccant until analysis. The remaining sample was centrifuged at 2000 rpm at room temperature in the field clinic. Serum was transferred to trace element-free microtubes and frozen immediately.

To collect cord blood samples and weight and measure the newborns as soon as possible after birth, a trained and standardized field-worker from the community was on-call $24 \mathrm{hr}$ a day. Women were asked to notify the field worker when they went into labor and to advice where they planned to deliver. Arrangements were made with local midwives, clinics and hospitals to permit the study field-worker into the delivery room (with the mothers consent). Once the cord had been clamped, it 
was allowed to drain and the sample represented a mix of cord venous and arterial blood. Sample processing and analysis were as described for maternal serum.

A breast milk sample was obtained at one month postpartum by electric pump (Engell Elite, Ameda Egnell, Switzerland). Milk was extracted from one breast until empty, with three samples during one day (approximately 10:00, 14:00 and 16:00 h); a minimum of two $\mathrm{h}$ after the infant was fed. When the final sample was obtained, the three samples were pooled and aliquots of $15 \mathrm{ml}$ obtained. The serum and human milk samples were stored temporarily in the field site at $-20^{\circ} \mathrm{C}$ then transferred within a week to the INSP laboratory and stored at $-70^{\circ} \mathrm{C}$ until analysis.

Serum and human milk retinol concentration and folate whole blood concentration were analyzed at the INSP Nutrition Laboratory and serum zinc concentration was analyzed at the Nutrition and Physiology Laboratories of the National Institute of Medical Sciences and Nutrition, Salvador Zubirán (Mexico, City). The quantitative measurement of serum and human milk retinol was determined by high-performance liquid chromatography (HPLC) in a Waters instruments (Waters Co., Milford, MA, USA). ${ }^{21}$ The milk sample was saponified with potassium hydroxide at $60^{\circ} \mathrm{C}$ during $45 \mathrm{~min}$ before the retinol extraction. Folate in whole blood was assessed using dried blood spots on filter paper using a microbiological assay. ${ }^{22,23}$ Serum zinc in maternal and cord blood was assessed using an atomic absorption spectrophotometer (AAS) (Perkin Elmer; model 2380, Norwalk, Connecticut, USA) with a wavelength of $213.9 \mathrm{~nm}$. A zinc standard (Sigma N.C. 2750, ST, Louis Missouri, USA) was used for each run. Before analysis, serum was defrosted and a dilution 1:5 with deionized water was made. The corresponding dilutions were made for the standard curve. The average of three readings from the AAS for each sample was obtained.

\section{Variable creation and statistical analysis}

Adherence to supplementation was assessed using the tablet consumption data recorded daily by the field worker and reported as the percentage of tablets offered that were consumed. Overweight was defined as BMI $>25^{24}$ at recruitment. An index of economic status was calculated using principal components analysis. ${ }^{16}$ This index provides a comparative classification of each household within the actual sample, but does not permit comparison with the broader society. All participants were from low income households (based on housing characteristics and household possessions).

Zinc deficiency was defined as serum zinc $<8.6$ $\mu \mathrm{mol} / \mathrm{L}$ at baseline, $<7.6 \mu \mathrm{mol} / \mathrm{L}$ at $32 \mathrm{wk}$ pregnancy. ${ }^{25}$
An appropriate cut-off point for one month postpartum has not been well defined, ${ }^{25}$ and we present, with caution, the prevalence of deficiency using the cut-off for non-pregnancy women in fasting blood samples $(<10.0$ $\mu \mathrm{mol} / \mathrm{L})$. As has been reported previously for Mexico, ${ }^{10}$ vitamin A deficiency (serum retinol $<0.35 \mu \mathrm{mol} / \mathrm{L}$ ) is very low in adult women. ${ }^{10}$ We defined vitamin A depletion/ deficiency as serum vitamin A concentration $<0.70$ $\mu \mathrm{mol} / \mathrm{L} .{ }^{26,27}$ The prevalence of folate deficiency (whole blood folate $<129.2 \mathrm{nmol} / \mathrm{L}$ ) is also low in Mexico ${ }^{11}$ and we present the prevalence of depletion/deficiency together as the concentration of whole blood folate $<147.29 \mathrm{nmol} / \mathrm{L}^{28}$

Demographic, socioeconomic, health and nutrition characteristics of the women were compared at baseline between the sub-sample included in this analysis and all other women assigned to treatment, regardless of whether they completed the study. In this way, we attempt to follow as close as possible an intention to treat analysis. The impact of supplementation on micronutrient status is assessed by comparing the change in serum zinc, retinol and whole blood folate between baseline and the 2 follow-up periods (32 weeks pregnancy and one month postpartum). Unadjusted comparisons of change in micronutrient status and percent deficiency were compared between supplementation groups using $\chi^{2}$ and Student's $t$ or Kruskal Wallis test. Multiple linear or logistic regression was used to assess the impact of supplementation on micronutrient status at 32 weeks pregnancy and one month postpartum without adjustment, and adjusting for baseline BMI, statistically significantly different in the full sample and micronutrient sub-sample between supplement groups at baseline. ${ }^{16}$ Since folate concentrations were non-normally distributed, all analyses were conducted with log transformed values. Cord blood zinc and breast milk retinol were compared between supplementation groups, with and without adjustment for potential confounders as described above. Data were analyzed with Stata 9.2 package (College Station, Texas, USA, Stata Corp., 2006).

\section{Results}

Of the 873 women assigned to treatment, ${ }^{16} 507$ (58.1\%) met the criteria of blood sample available to calculate at least one difference (baseline to 32 weeks and / or baseline to one month postpartum) or cord blood or breast milk for assessment of at least one nutrient and were included in this analysis. Samples were available for one of the above mentioned analysis only from 89 women and 142, 92 and 103 women contributed samples for 3 , 4 or 5-8 analysis, respectively. Duration of pregnancy, 
Table III

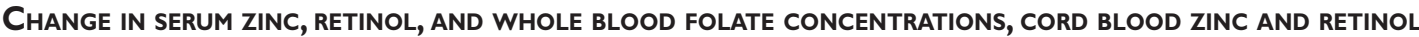
AND BREAST MILK RETINOL CONCENTRATIONS BY TREATMENT GROUP

\begin{tabular}{lcccc} 
Iron only & \multicolumn{3}{c}{ Multiple micronutrients } \\
$n$ & Mean $\pm S D^{*}$ & $n$ & Mean $\pm S D$ & p-value
\end{tabular}

Serum zinc (maternal blood), $\mu \mathrm{mol} / \mathrm{L}$

\begin{tabular}{ccccccc} 
Change from baseline to 32 wks pregnancy & 158 & $-3.2 \pm 4.5$ & 132 & $-3.0 \pm 2.7$ & 0.78 \\
\hline Change from baseline to I mo postpartum & 138 & $-2.4 \pm 3.4$ & 137 & $-2.7 \pm 3.2$ & 0.44 \\
\hline Serum zinc (umbilical cord blood), $\mu \mathrm{mol} / \mathrm{L}$ & 78 & $14.4 \pm 2.4$ & 62 & $14.0 \pm 2.6$ & $0.3 \mid$
\end{tabular}

Serum retinol (maternal blood), $\mu \mathrm{mol} / \mathrm{L}$

\begin{tabular}{|c|c|c|c|c|c|}
\hline Change from baseline to 32 wks pregnancy & 101 & $-0.13 \pm 0.27$ & 95 & $-0.15 \pm 0.30$ & 0.72 \\
\hline Change from baseline to I mo postpartum & 133 & $0.43 \pm 0.34$ & 127 & $0.41 \pm 0.37$ & 0.64 \\
\hline Serum retinol (umbilical cord blood), $\mu \mathrm{mol} / \mathrm{L}$ & 79 & $0.65 \pm 0.20$ & 63 & $0.66 \pm 0.22$ & 0.69 \\
\hline Breast milk retinol (I mo postpartum), $\mu \mathrm{mol} / \mathrm{L}$ & 122 & $\begin{array}{c}0.57 \\
(0.35,0.87)\end{array}$ & 115 & $\begin{array}{c}0.63 \\
(0.38,0.84)\end{array}$ & 0.92 \\
\hline
\end{tabular}

Whole blood folate (maternal blood), nmol/L

Change from baseline to I mo postpartum

69

$-56.9 \pm 153.2$

63

* Data for breast milk retinol presented as median (interquartile range)

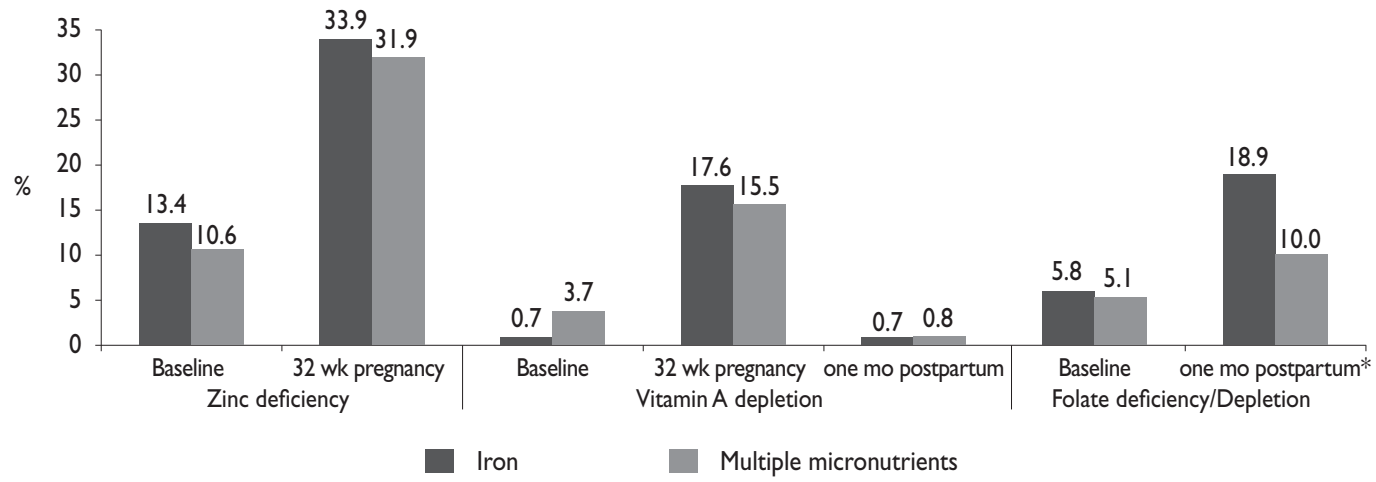

Figure I. Prevalence of zinc deficiency and vitamin A and folate depletion during pregnancy and one month POSTPARTUM BY TREATMENT GROUP. ${ }^{A, B}$. SOLID BARS REPRESENT IRON ONLY, ${ }^{A}$ AND OPEN BARS, MULTIPLE MICRONUTRIENTS. ${ }^{B}$ ZINC DEFICIENCY WAS DEFINED AS SERUM ZINC <8.6 MOL/L AT BASELINE AND <7.6 MOL/L AT 32 WK OF PREGNANCY, VITAMIN A DEPLETION AS SERUM RETINOL $<0.70 \mathrm{MOL} / \mathrm{L}$ AND FOLATE DEFICIENCY/DEPLETION AS WHOLE BLOOD FOLATE <147.29 NMOL/L. $* 0.05<P<0.10$ BETWEEN GROUPS.

(18.5\% in iron group and $10.0 \%$ in MM group) (Figure 1). In unadjusted group comparisons there was a nonstatistically significant trend $(p=0.09)$ towards a lower prevalence of folate depletion/deficiency in the MM group than the Fe group.

\section{Discussion}

Supplementation with multiple micronutrients during pregnancy did not improve zinc or vitamin A status during pregnancy or in the early postpartum period 
compared to supplementation with iron only. There is some suggestion that multiple micronutrient supplementation may result in lower risk of folate deficiency / depletion at one month postpartum. The results of this randomized controlled trial provide evidence for the lack of effect of multiple micronutrient supplementation on biochemical indicators of zinc, vitamin A and folate status among pregnant women where the prevalence of deficiency in early pregnancy is low for folate and vitamin $\mathrm{A}$, and moderate for zinc.

We included in this study only the subsample of women from whom we had blood sample of micronutrient biochemical analysis, which is not the same as loss to follow-up, given that these are complete follow-up for each micronutrient studied. We found that there were differences in some characteristics among the sub-sample included in this analysis and those excluded, such as compliance, duration of pregnancy and hemoglobin concentration. The last one, being significantly lower $(p<$ 0.05 ) among women included in this study, resulting, probably in a group of women with a greater potential to respond to supplementation. However, we did not find improvement in iron status in this subsample.

Unfortunately, we do not have evidence whether the MM supplements may have had additional benefits for the women. For example, in a study from Nepal, a positive impact of iron+folic acid+zinc but not multiple micronutrient supplements on the prevalence ratio of sub-clinical infections was reported. ${ }^{15}$

To date, few studies have reported the impact of multiple micronutrient supplementation during pregnancy on biochemical indicators. In Nepal, women consuming multiple micronutrient supplements had better vitamin $\mathrm{E}$ and A status compared to controls at 32 weeks pregnancy. ${ }^{29}$ Results are not presented in this study for serum values of other micronutrients. A latter study in the same country reported that supplementation with multiple micronutrients improved folate, vitamin $\mathrm{B}_{12}$, $\mathrm{B}_{6}$ and riboflavin status between baseline and the third trimester compared to controls receiving vitamin $\mathrm{C}$ only. ${ }^{15}$ Contrary to our findings, serum zinc improved in the group receiving multiple micronutrients, but not in those receiving folic acid, iron and zinc without other micronutrients. In general, the women who participated in the studies in Nepal had worse zinc, folate and vitamin A status than the women in Mexico, which may explain the difference in findings.

It is unlikely that the lack of impact observed here is related to compliance with supplementation. Compliance was high (over $80 \%$ in both groups) and began at an average of nine weeks pregnancy, leaving ample time for impact. In the case of vitamin A there may have been little potential to respond given the low prevalence of depletion and lack of overt deficiency in the population. A similar prevalence of depletion was reported a large national nutrition survey which was conducted during the same time period (1999) ${ }^{11}$ and suggests that vitamin A deficiency is no longer a public health problem in adult women in Mexico, even during pregnancy.

Given the relatively high zinc content of the MM tablet $(15 \mathrm{mg})$ and high compliance, the lack of impact on serum zinc and the increase in the prevalence of deficiency is surprising. Post-hoc power calculations suggest that we had power $(>80 \%)$ to detect a difference in the mean change in zinc concentration of $1.1 \mu \mathrm{mol} / \mathrm{L}$. One study in Peruvian pregnant women ${ }^{30}$ found that supplementation with $15 \mathrm{mg}$ of zinc plus $60 \mathrm{mg}$ of iron and $250 \mu \mathrm{g}$ of folate during pregnancy improved maternal zinc status by $0.4-1.7 \mu \mathrm{mol} / \mathrm{L}$ between 28 y $30 \mathrm{wk}$ pregnancy compared to supplementation with iron/ folate only. This population had a lower mean serum zinc concentration $(10.6 \pm 2.1 \mu \mathrm{mol} / \mathrm{L})$ that the women in our study $(11.9 \pm 2.8 \mu \mathrm{mol} / \mathrm{L})$ at baseline. Serum zinc concentration is normally low during pregnancy and is highly affected by hemodilution among other factors related to pregnancy. ${ }^{25}$ It is possible that these factors outweighed the impact of supplementation in this sample of women with marginal deficiency. The extremely high prevalence of deficiency at one month postpartum (almost 80\%) seems improbable in this population and the appropriateness of using the cut-off point for non-pregnant women at this time should be evaluated. Even if the actual prevalence is overestimated, we have no reason to believe that the use of this cut-off point would differentially affect the supplement groups and thus we conclude that supplementation with MM did not have an impact on the prevalence of zinc deficiency.

Another possibility for the lack of effect of supplementation on serum zinc concentration is the interaction between nutrients in the supplement, particularly zinc and iron. Recent studies have reported reduced zinc absorption from food ${ }^{31}$ and from supplements ${ }^{32}$ in the presence of supplemental iron. In both studies, iron content of the supplement was considerably higher than zinc content (100 $\mathrm{mg}$ of supplemental iron in the first with no zinc and $60 \mathrm{mg}$ of iron and $15 \mathrm{mg}$ of zinc in the second). When the iron:zinc ratio is very high, for example 25:1, ${ }^{33}$ zinc absorption is diminished. Others ${ }^{34}$ have reported that $25 \mathrm{mg}$ of zinc sulphate consumed with $25 \mathrm{mg}$ of iron (1:1 ratio) in a watery solution results in reduced plasma zinc concentration compared to supplementation with zinc without iron. This effect was magnified when the dose of iron is of 50 or $75 \mathrm{mg}$, that is, when the ratio of iron to zinc is 2:1 or 3:1. In the supplement distributed in our study, the ratio of iron 
to zinc was 4:1 and it is possible that this resulted in an inhibition of zinc absorption.

Multiple micronutrient supplementation may have prevented a worsening of folate status during pregnancy, compared to iron only supplementation. Dietary intake of folate during pregnancy did not differ between supplementation groups at baseline, 32 weeks or one month postpartum, ${ }^{35}$ further supporting the possibilite that the difference in folate status between groups, albeit small, can be attributable to the supplement. The folate content of the supplement used here was lower than that reported by others in similar studies. ${ }^{13}$ It is possibly that higher doses of folate are needed to significantle improve status in this type of population with only marginal deficiency. Clear benefits of improved folate status before and during pregnancy have been documented, including prevention of neural tube defects, fetal death, among other outcomes, ${ }^{36}$ and possibly, reduced risk of low birth weight, preterm delivery and intrauterine growth retardation. ${ }^{37,38}$ It is important to note that at the time that this study was conducted, standard practice during pregnancy in Mexico included supplementation with iron only, not iron plus folate -a policy which has since been modified.

Micronutrient malnutrition during pregnancy, particularly zinc and iron deficiency, continue to be important public health problems among the poor in Mexico. Although the prevalence of folate deficiency is low and severe deficiency is rare, it is still of concern due to the important implications for pregnancy outcomes. We report here and previously ${ }^{17}$ no clear benefit of multiple micronutrient supplementation over iron only supplementation for zinc, iron, vitamin A or folate status during pregnancy or early postpartum. Furthermore, even in this sample with high compliance, consumption of multiple micronutrients did not eradicate micronutrient deficiency. In populations like Mexico and many other middle income and developing countries where micronutrient deficiencies exist in non-pregnant women of reproductive age, strategies to improve status before women get pregnant, such as food fortification are clearly needed. The impact of multiple micronutrient supplements with lower doses of iron and an iron:zinc ratio closer to one on iron and zinc status during pregnancy should be explored. The potential of other interventions such as home fortification should also be explored. Moreover the programs for supplementation with micronutrients would be desirable are directed specifically to population, where magnitude and severity of nutritional deficiencies are a major public health problem.

\section{References}

I. King JH. Determinants of maternal zinc status during pregnancy.Am J Clin Nutr 2000;71:1334S-1343S.

2. Keen LC, Hurley LS. Zinc in reproduction: Effects of deficiency on fetal and postnatal development In: Mills CF, editor. Zinc in human biology, ILSI Human Nutrition Reviews. New York: Springer, 1989; 183-21 I.

3. Tamura T, Goldenberg RL. Zinc nutriture and pregnancy outcome. Nutr Research 1996;16:139-181.

4. Scholl T, Hediger M, Schall J, Fischer R, Khoo CS. Low zinc intake during pregnancy: its association with preterm and very preterm delivery. Am J Epidemiol 1993; 137:I II5-I I 24.

5.Allen LH. Multiple micronutrients in pregnancy and lactation: an overview. Am J Clin Nutr 2005;81:1206S-12I2S.

6. Garn SF, Ridella SA, Petzold AS, Falkner F. Maternal hematologic levels and pregnancy outcomes. Semin Perinatol I981;5:155-I62.

7. Mola G, Permezel M,Amoa AB, Klufio CA.Anaemia and perinatal outcome in Port Moresby.Aust N Z J Obstet Gynaecol 1999;39:31-34. 8. Czeizel AE, Dudas I. Prevention of the first occurrence of neural-tube defects by periconceptional vitamin supplementation. N Engl J Med 1992;327:1832-1835.

9. Mills JL, McPartlin JM, Kirke PN, Lee YJ, Conley MR, Weir DG, et al. Homcysteine metabolism in pregnancies complicated by neural-tube defects. Lancet 1995;345(8943): I49-I5I.

I0.Villalpando S, García-Guerra A, Ramírez-Silva Cl, Mejía-Rodríguez F, Matute G, Shamah-Levy T, et al. Iron, zinc, and iodide status in Mexican children under 12 years and women $12-49$ years: A probabilistic national survey. Salud Publica Mex 2003;45:S520-S529.

I I.Villalpando S, Montalvo-Velarde I, Zambrano N, García-Guerra A, Ramírez-Silva Cl, Shamah-Levy T, et al. Vitamins A, and C and folate status in Mexican children under 12 years and women $12-49$ years: A probabilistic national survey. Salud Publica Mex 2003;45:S508-S5 19. 12. Haider BA, Bhutta ZA. Multiple-micronutrient supplementation for women during pregnancy. Cochrane Database Syst Rev 2006 Oct 18;(4):CD004905.

13. Hindle LJ, Gitau R, Filteau SM, Newens KT, Osrin D, Costello $\mathrm{AM}$, et al. Effect of multiple micronutrient supplementation during pregnancy on inflammatory markers in Nepalese women. Am J Clin Nutr 2006;84: 1086-1092.

14. Christian P, Osrin D, Manandhar DS, Khatry SK, de L Costello ZM, West KP Jr.Antenatal micronutrient supplements in Nepal. Lancet 2005;366(9487):7II-7II.

15. Christian P, Jiang T, Khatry SK, LeClerq SC, Shrestha SR, West KP. Antenatal supplementation with micronutrients and biochemical indicators of status and subclinical infection in rural Nepal.Am J Clin Nutr 2006;83:788-794.

16. Ramakrishnan U, Gonzalez-Cossio T, Neufeld LM, Rivera J, Martorell R. Multiple micronutrient supplements during pregnancy do not increase birth size compared to iron-only supplements: a randomized controlled trial a semi-rural community in Mexico.Am J Clin Nutr 2003;77:720-725. 17. Ramakrishnan U, Neufeld LM, Gonzalez-Cossio T,Villalpando S, García-Guerra A, Rivera J, et al. Multiple micronutrient supplements during pregnancy do not reduce anemia or improve iron status compared to iron-only supplements in semirural Mexico.J Nutr 2004;134:898-903. 18. Ramakrishnan U, Gonzalez-Cossio T, Neufeld LM, Rivera J, Martorell R. Effect of prenatal multiple micronutrient supplements on maternal weight and skinfold changes: a randomized double-blind clinical trial in Mexico. Food Nutr Bull 2005;26:273-280.

19. National Research Council (U.S.). Subcommittee on the Tenth Edition of the Recommended Dietary Allowances. Washington. DC: The National Academy Press, 1989. 
20. Neufeld L, Haas J, Grajeda R, Martorell R. Last menstrual period provides the best estimate of gestation length for women in rural Guatemala. Paediatr Perinat Epidemiol 2006;20:290-298.

21. Stoltzfus $R$, Underwood B. Breastmilk vitamin $A$ as an indicator of vitamin A status of women and infants. Bull WHO 1995;73:703-7I I.

22. O'Broin SD, Gunther EW. Screening of folate status with the use of dried blood spots on filter paper.Am J Clin Nutr 1999;70:329-367. 23. O'Broin SD, Kelleher B. Microbiological assay on microtitre plates of folate in serum and red cells.J Clin Pathol 1992;45:344-347. 24. World Health Organization (WHO) Expert Committee. Physical status: the use and interpretation of anthropometry, p. 47 WHO Technical Report Series 854. Geneva:World Health Organization, 1995.

25. International Zinc Nutrition Consultative Group (IZiNCG). Technical Document \#I.Assessment of the risk of zinc deficiency in populations and options for its control. Hotz C and Brown KH (eds). Food Nutr Bull 2004;25:S94-S203.

26. Pilch SM. Assessment of the vitamin A nutritional status of the US population based on data collected in the Health and Nutrition Examination Surveys. Bethesda, MD: Life Science Research Office, Federation of American Biological Societies, 1985.

27. World Health Organization. Indicators for assessing vitamin A deficiency and their application in monitoring and evaluating intervention programs.WHO/NUT/96. I0. Geneva:World Health Organization, 1996. 28. Wagner C. Folic acid. In: Brown M (ed). Present knowledge in Nutrition. $5^{\text {th }}$ Edition. Washington DC:The Nutrition Foundation, Inc. 1984:332-346.

29. Osrin D, Vaidya A, Shrestha Y, Baniya RB, Manandhar DS, Adhikari RK, et al. Effects of antenatal multiple micronutrient supplementation on birthweight and gestational duration in Nepal: double-blind, randomized controlled trial. Lancet 2005;365(9463):955-962.

30. Caulfield LE, Zavaleta N, Figueron A.Adding zinc to prenatal iron and folate supplements improves maternal and neonatal zinc status in a Peruvian population. Am J Clin Nutr 1999;69:1257-1263.

3I. Harvey LF, Dainty JR, Hollands WJ, Bull VJ, Hoogewerff JA, Foxall RJ, et al J. Effect of high-dose iron supplements on fractional zinc absorption and status in pregnant women. Am J Clin Nutr 2007;85:I3I-I36.

32. O'Brien KO, Zavaleta N, Caulfield LE, Wen J,Abrams SA. Prenatal iron supplements impair zinc absorption in pregnant Peruvian women.J Nutr 2000; 130:225I-2255.

33. Lönnerdal B. Dietary factors influencing zinc absorption.J Nutr 2000;130:1378S-1383S.

34. Solomons NW, Jacob RA. Studies on the bioavailability of zinc in humans: effect of heme and nonheme iron on the absorption of zinc.Am J Clin Nutr 1981;34:475-482.

35. Flores ML, Neufeld LM, González-Cossío T, Rivera J, Martorell R, Ramakrishnan U. Multiple micronutrient supplementation and dietary energy intake in pregnant women. Salud Publica Mex 2007;49:190-198. 36. Tamura T, Picciano MF. Folate and human reproduction. Am J Clin Nutr 2006;83:993-1016.

37. Scholl TO, Hediger ML, Schall JI, Khoo CS, Fischer RL. Dietary and serum folate: their influence on the outcome of pregnancy.Am J Clin Nutr 1996;63:520-525.

38. Lindblad B, Zaman S, Malik A, Martin H, Ekstrom AM, Amu S, et al. Folate, vitamin BI2, and homocysteine levels in South Asian women with growth-retarded fetuses. Acta Obstet Gynecol Scand 2005;84:1055-106I. 